\title{
Editorial
}

\section{eCAM: Moving Forward}

\section{Edwin L. Cooper}

Laboratory of Comparative Neuroimmunology, Department of Neurobiology, David Geffen School of Medicine at UCLA, University of California, Los Angeles, CA 90095-1763, USA

In any endeavor, there may be highs and lows and usually mixes. Strengths are needed and summoned in a way to assuage the difficulties. We have enjoyed an auspicious beginning. Volume 4 has enjoyed a good year, continuous exposure to international audiences, enthusiasm expressed by authors and observers and most importantly the publication of our first Supplement devoted to the Vinci Symposium (1). In fact that was only one of the several gatherings devoted exclusively to $e C A M$. This is the last issue of 2007 and it seems appropriate to inform our readers of a few efforts to increase their visibility of $e C A M$. Thus I have been able to attend the following meetings, as invited speaker, or member of organizing committees. Here is a partial list for your perusal:

The 4th International Conference of the Society for Integrative Oncology: 15-17 November 2007, San Francisco, CA, USA, (http://www.integrativeonc.org/); The World Summit for Harmonization of Traditional, Alternative and Complementary Medicine, 7-11 November 2007, Lima, Peru (http://www.cmp.org.pe/); European Traditional Medicine - International Conference, 5-6 October 2007, Vinci, Italy (http://www.usl11.tos.it/ etm2007/index.html); ALPHA 2007 - Age And Alternative Medicine, 31 August to 1 September 2007, Greifswald, Germany (http://www.medizin.uni-greifswald.de/intensiv/ alpha2007.pdf); The First Regional Scientific Conference on Traditional Arabic and Islamic Medicine, 8-10 August 2007, Amman, Jordan (http://www.arabic-islamic-medicine. com/); VII International Conference on Biotherapy, 21-24 June 2007, Seoul, Korea (http://www.icb2007.org/ main/index.php?page $=$ home) .

For reports and all correspondence: Edwin L. Cooper, $\mathrm{PhD}, \mathrm{ScD}$, Distinguished Professor, Laboratory of Comparative

Neuroimmunology Department of Neurobiology, David Geffen School of Medicine at UCLA, University of California, Los Angeles, CA 90095-1763, USA. Tel: + 1-310-825-9567; Fax: +1-310-825-2224;

E-mail: ecam@mednet.ucla.edu
On another positive note to this year, it is a pleasure to acknowledge the publication of two books: Giarelli, Guido, Paolo Roberti di Sarsina, Bruno Silvestrini (a cura di) Edwin L. Cooper Prefazione; Amedeo Bianco, Postfazione. Le Medicine Non-Convenzionali in Italia, Franco Angeli, 2007, 412 pages (2); Paolo Marandola and Francesco Marotta con il contributo di Woo Chul Moon; Prefazione di Umberto Veronesi. Il Manifesto Dela Lunga Vita. Sperling and Kupfer, 2007, 533 pages (3). Nearly 100 authors included papers on aging by Edwin L. Cooper and Shinji Kasahara, as well as Francesco Marotta. The paper by Emilio Minelli deals specifically with Complementary Medicine.

For another high note, we are now coming to the end of the current contract with ISMET in Spain for an online excerpted Spanish language edition of $e C A M$, and also renewing the contract with ISMET for 2 years. I confirmed that ISMET have translated 16 articles during the last 12-month period, and expect to translate a maximum of 20 articles per year over the next 2 years. The Spanish language edition of selected papers is available at the open-access journal website, Digitalis, http://www.e-digitalis.com. I consider this a major contribution due to the extensive use of the Spanish language.

It is a pleasure to acknowledge the efforts of Professor Lonnie Zeltzer, MD, Member of the Editorial Board, who has worked with diligence to put together several papers that concentrate on the subject of Yoga, clearly recognized as a vital component of Complementary and Alternative Medicine, Integrative Medicine and of course $e C A M$. A brief definition seems appropriate to set the tone for reading. Yoga originates from a Sanskrit word that means yoke or union in ancient India. It is one of the longest surviving philosophical systems in the world as old as 5000 years. According to some estimates, artifacts detailing yoga postures have been found in India dating back to over 3000 B.C. Yoga is traditionally a method 
joining the individual self with the Divine, Universal Spirit, or Cosmic Consciousness. There are physical and mental exercises designed to help achieve this goal, often referred to as self-transcendence or enlightenment. On the physical level, yoga postures (called asanas in Sanskrit) are designed to tone, strengthen and align the body. These postures are performed in a way that the spine may become supple and healthy. This also promotes blood flow to all organs, glands and tissues, thus promoting and maintaining healthy bodily systems. On the mental level, breathing techniques (pranayama) and meditation (dyana) that are designed to quieten, clarify and discipline the mind are used in Yoga. According to experts, Yoga is not a religion but a way of living aimed at aiding health and peace of mind. These are the laudable and pleasant outcomes of Yoga.

Now for those that are not so pleasant. We had expected an impact factor all along and even there were predictions of an impact factor (4). Unfortunately, in June $e C A M$ did not receive an impact factor for 2006. After direct contact with ISI, it has been found that ISI had not indexed the first volume of $e C A M$, which means that there was not enough information for an impact factor to be calculated. Copies of volume 1 have now been sent again to ISI, and it is hoped that an impact factor will be calculated retrospectively. With the disappointment a resolution shall appear in volume 5 .

Recently we received the disappointing news that our Founding International Administrator, Patty Willis would resign. She has written to the Editorial Board regarding this, and some members have expressed surprise and sorrow, vowing to do all to reinstate her. We will miss Patty extremely because of her dedication, strength, intelligence and commitment to $e C A M$. Our friendship remains and I often reminisce about our travels to distant laboratories, to meetings in foreign lands all in our joint attempts to increase the visibility of $e C A M$ and to promote it among active CAM workers. Patty helped to edit the book Complementary and Alternative Approaches to Biomedicine (5) and indeed imprinted the book and $e C A M$ indelibly with her wisdom and strong interest.

I have extracted some lines from Patty's essay entitled Beginnings written roughly 5 years ago: 'November 7th arrived quickly and invitees gathered from India, China, Taiwan, Europe and The United States, each feeling like an old friend after our months of correspondence. They all brought their unique histories and expertise, coming together for the first time in the conference halls in Kanazawa. Preoccupations behind the scenes kept me from attending all the meetings but when I did, what moved me most was the energy and flow of ideas. In a favorite Native American legend, the energy of the movement of a dancing rabbit generates the creation of humankind. All those who participated in the symposium provided the energy that would gain speed and evolve into a new creation, an international journal dreamed of many years ago' (6). So Patty, it is with happiness and gratitude for all that you did. This vacuum caused by your departure has not been filled and probably will never be because of your uniqueness. With profound appreciation I salute you and wish for all good fortune to become yours!

Now for news that is less sad, volume 5 promises to be somewhat unique and something that Patty and I shared in our mutually agreeable and complementary visions. TCM is more popular and often considered to be the yardstick that measures practices of integrative or holistic medicine. Determined to bridge cultural barriers, from the Pacific (Kampo, Korea) forward to penetrating the Indian subcontinent, I accepted an invitation to lecture at the 2nd Ayurvedic Congress in Pune, India in 2006. Presenting an intense writer's workshop, I contacted many students and professors and entered this often forgotten bastion of integrative medicine, Ayurveda, a multi-millennia, integrative medical practice in fact by some estimates, perhaps older than TCM. This initiative is responsible for and the inspiration for the new cover of volume 5 as well as lead papers and appointments of new members of the Editorial Board.

\section{References}

1. Vinci Symposium. Avaiable at: http://ecam.oxfordjournals.org/ content/vol4/suppl 1/index.dtll.

2. Guido G, Roberti di Sarsina P, Silvestrini B, Cooper EL, Bianco A. Le Medicine Non-Convenzionali in Italia. Milan: Franco AngeliL, 2007.

3. Marandola P, Marotta F, Moon WC, Veronesi U. Il Manifesto Dela Lunga Vita. Milano: Sperling Kupfer, 2007.

4. Cooper EL. On the road to an impact factor for $e C A M$. Evid Based Complement Alternat Med 2007;4:1-2.

5. Cooper EL, Yamaguchi N (eds). Complementary and Alternative Approaches to Biomedicine. Advances in Experimental Medicine and Biology, Vol. 546. New York: Kluwer Academic/Plenum Publishers, 2004.

6. Willis PC. Beginnings. In: Cooper EL, Yamaguchi N (eds). Complementary and Alternative Approaches to Biomedicine. Advances in Experimental Medicine and Biology, Vol. 546. New York: Kluwer Academic/Plenum Publishers, 2004, 5-6. 


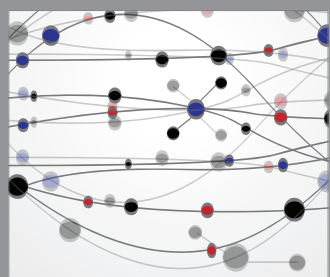

The Scientific World Journal
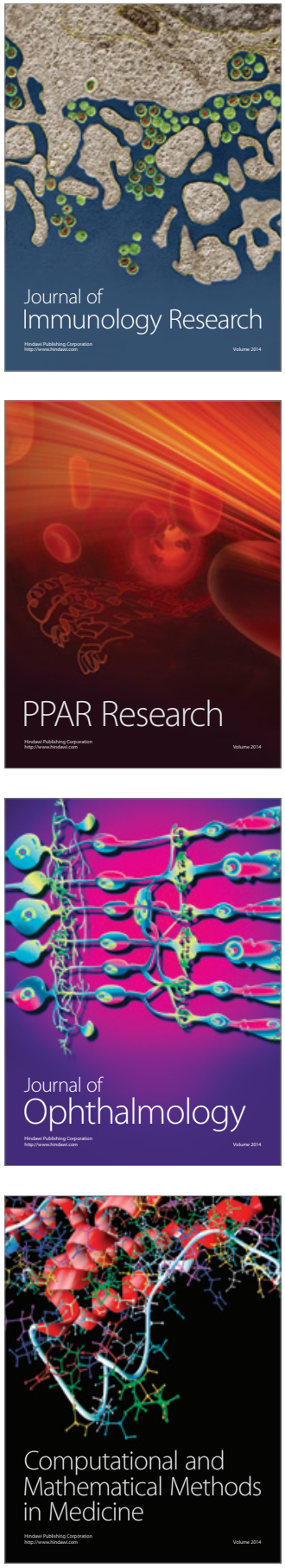

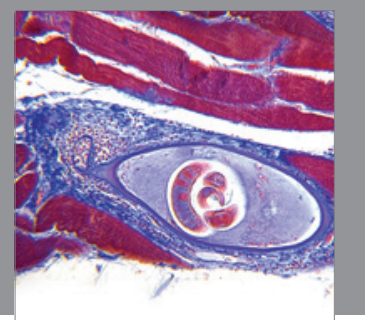

Gastroenterology

Research and Practice
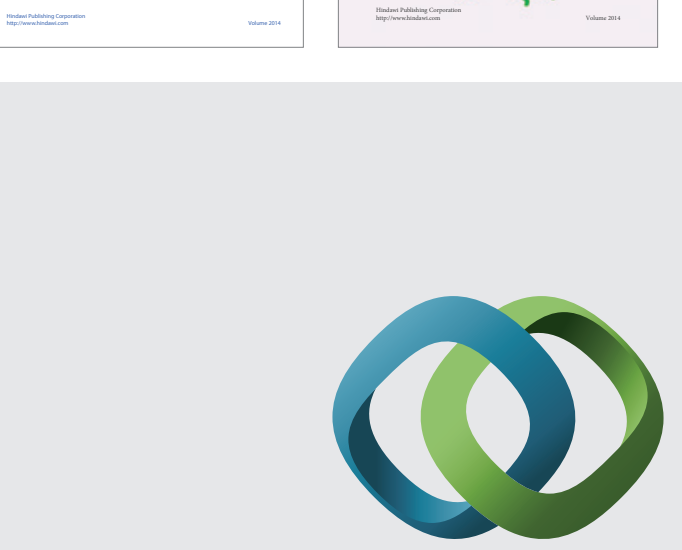

\section{Hindawi}

Submit your manuscripts at

http://www.hindawi.com
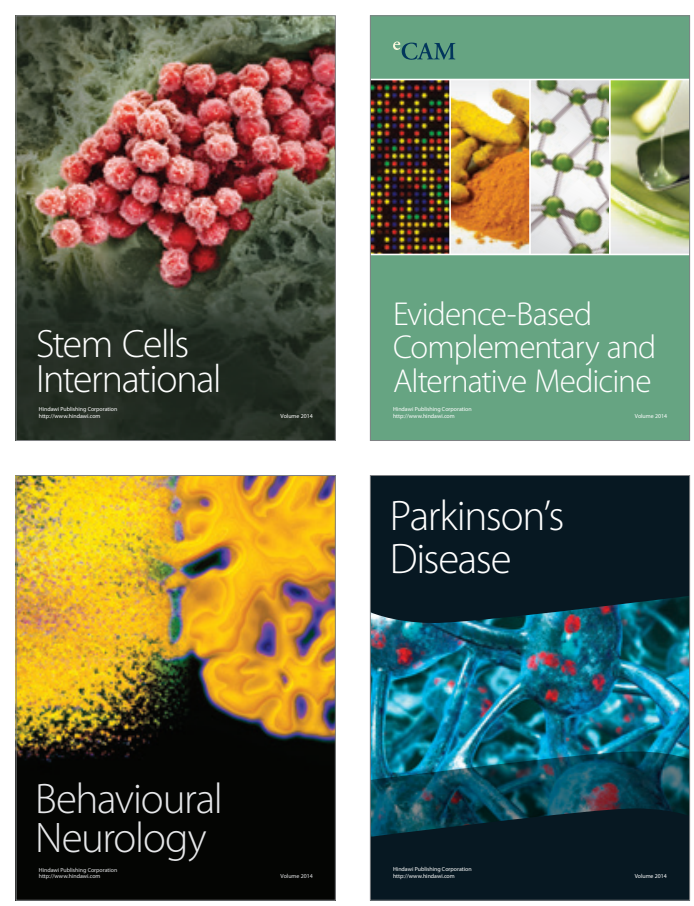

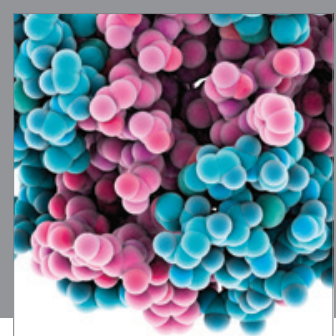

Journal of
Diabetes Research

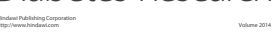

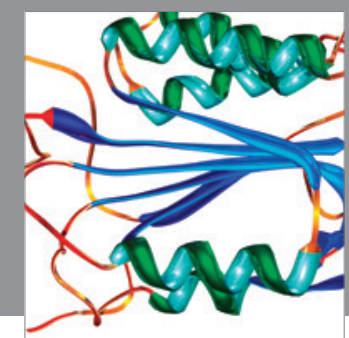

Disease Markers
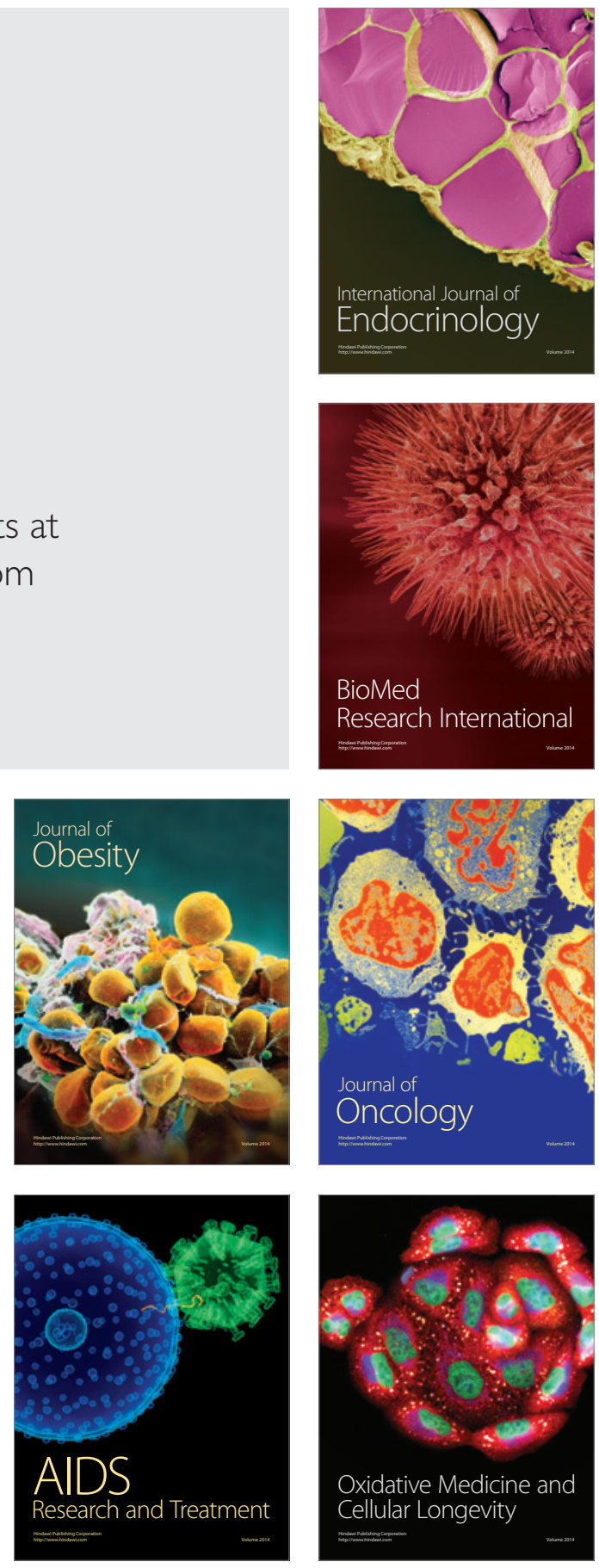